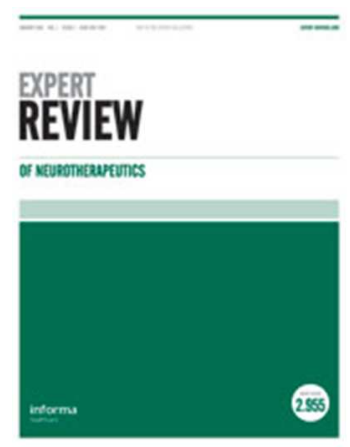

\title{
Targeting astrocytes in major depression
}

\begin{tabular}{|r|l|}
\hline Journal: & Expert Review of Neurotherapeutics \\
\hline Manuscript ID & ERN-2015-0099.R1 \\
\hline Manuscript Type: & Reviews \\
\hline Keywords: & $\begin{array}{l}\text { Astrocyte, Major depression, mechanism of drug action, SSRI, } \\
\text { neuropsychiatric diseases }\end{array}$ \\
\hline
\end{tabular}

\section{SCHOLARONE"}

Manuscripts 
ERN 1511

REVIEW

US ENGLISH

\section{Targeting astrocytes in major depression}

Liang Peng ${ }^{1 *}$, Alexei Verkhratsky $\mathrm{y}^{2,3,4}, \mathrm{Li} \mathrm{Gu}^{1}$ and Baoman $\mathrm{Li}^{1}$

${ }^{1}$ Laboratory of Metabolic Brain Diseases, Institute of Metabolic Disease Research and Drug Development, China Medical University, Shenyang, P. R. China, and ${ }^{2}$ Faculty of Life Science, The University of Manchester, Manchester, UK, ${ }^{3}$ Achucarro Center for Neuroscience, IKERBASQUE, Basque Foundation for Science, 48011 Bilbao, Spain \& Department of Neurosciences, University of the Basque Country UPV/EHU and CIBERNED, Leioa, Spain; ${ }^{4}$ University of Nizhny Novgorod, Nizhny Novgorod 603022, Russia.

Running title: Therapeutic potential of astroglia in major depression

Send correspondence to:

Professor Liang Peng, Laboratory of Brain Metabolic Diseases, Institute of Metabolic Disease Research and Drug Development, China Medical University, No. 92 Beier Road, Heping District, Shenyang, P.R. China. e-mail: hkkid08@yahoo.com

OR

Professor Alexei Verkhratsky Faculty of Life Science, The University of Manchester, Manchester, UK email: Alexej.Verkhratsky@manchester.ac.uk 


\begin{abstract}
Astrocytes represent a highly heterogeneous population of neural cells primarily responsible for the homeostasis of the central nervous system. Astrocytes express multiple receptors for neurotransmitters, including the serotonin $5-\mathrm{HT}_{2 B}$ receptors and interact with neurones at the synapse. Astroglia contribute to neurological diseases through homeostatic response, neuroprotection and reactivity. In major depression, astrocytes show signs of degeneration and are decreased in numbers, which may lead to a misbalance in neurotransmission and aberrant synaptic connectivity. In this review we summarise astroglia-specific effects of major antidepressants and outline future strategies for astroglia-specific therapy in neuropsychiatric disorders.
\end{abstract}

Key words: astrocytes; major depression; mechanism of drug action; SSRI; neuropsychiatric diseases 


\section{INTRODUCTION: ASTROCYTES MAINTAIN THE INTEGRITY OF THE BRAIN}

The central nervous system (CNS) tissue is an intricate network of many cell types, which are represented by neurones, neuroglia, pericytes, muscle and endothelial cells of brain vessels, ependymal cells etc. The neuroglia conceptually are defined as a heterogeneous population of cells of neural and non-neural origin which provide for homeostasis and defence of the CNS [1, 2]. Neuroglia are sub-classified into astrocytes, oligodendrocytes, NG2 glia (all are of neuroepithelial, ectodermal origin, also known as macroglia) and microglial cells of mesodermal, myeloid descent [1, 2]. Astrocytes are highly heterogeneous glial cells, which populate the brain and spinal cord and are primarily responsible for homeostasis of the CNS [2].

Astrocytes significantly contribute to the brain metabolism (see [3] for comprehensive review on astroglial bioenergetics) and are central elements for potassium ion $\left(\mathrm{K}^{+}\right)$buffering, neurotransmitter homeostasis, maintenance and regulation of synaptic transmission and CNS metabolism. Astrocytes are the only cells in the brain capable of synthesizing glutamate from glucose, and are essential for the supply of glutamatergic and GABA-ergic neurones with glutamine that is subsequently converted into glutamate and GABA [4]. In the glutamate-glutamine cycle, glutamate released from neurones is mainly taken up into astrocytes by $\mathrm{Na}^{+}$-dependent transporters EAAT1/2 (excitatory amino acid transporters 1 and 2 - see [5]). In astrocytes glutamate (together with the de novo synthesized glutamate) is converted to glutamine, which is subsequently transported to neurones through the system of cell-specific glutamine transporters; in neuronal terminals glutamine serves as a precursor for glutamate and GABA [6] this cycles are known as glutamate- glutamine and GABA glutamine shuttles. Astrocytes themselves are also capable of releasing glutamate via different mechanisms, including $\mathrm{Ca}^{2+}$-regulated exocytosis and diffusion through membrane channels [7].

Astrocytes express a multitude of neurotransmitter receptors, including NMDA and non-NMDA glutamate receptors, purinoceptors, serotonin $\left(5-\mathrm{HT}_{2}\right)$ receptors and an- and ?]-adrenergic receptors [8], although expression of the receptors varies substantially between brain regions [9]. Stimulation of neurotransmitter receptors in astrocytes activates cytosolic and nuclear signalling pathways, altering cellular functions as well as gene expression. Many astroglial receptors are linked to an increase in free cytosolic calcium concentration $\left(\left[\mathrm{Ca}^{2+}\right]_{\mathrm{i}}\right)$, which can activate secretion of numerous astroglia-derived signalling molecules that may in turn modulate neuronal activity. Astroglial $\mathrm{Ca}^{2+}$ signals can also propagate through astrocytic network as $\mathrm{Ca}^{2+}$ waves [10]. Astrocytes also utilise transient fluctuations in intracellular $\mathrm{Na}^{+}$ concentration to regulate numerous plasmalemmal transporters [11]. Pharmacological agents interacting with neurotransmitter receptors can therefore influence neuronal-astroglial communication. Astrocytes are important source of the brain cytokine network that is involved in the pathogenesis of various psychoses [12]. Three astrocytic membrane proteins (the Na,K-ATPase, the sodium-potassium chloride co-transporter NKCC1 and inward rectifier $\mathrm{K}_{\mathrm{ir}} 4.1$ channels) are involved in extracellular $\mathrm{K}^{+}$buffering. The $\mathrm{Na}$, K-ATPase is the main $\mathrm{K}^{+}$transporter at $\left[\mathrm{K}^{+}\right]_{\mathrm{e}}$ of $\sim 10 \mathrm{mM}$ as has been shown by inhibition 
with ouabain (for review, see [13] and references therein). At higher $\left[\mathrm{K}^{+}\right]_{\mathrm{e}}, \mathrm{NKCC1}$ plays the dominant role, as shown by inhibition with bumetanide, an inhibitor of the co-transporter NKCC1. The NKCC1, however, it is metabolically driven by ion gradients established by the $\mathrm{Na}$,K-ATPase. The $\mathrm{K}_{\mathrm{ir}} 4.1$ channels are differentially involved in $\mathrm{K}^{+}$buffering in various regions of the brain.

The importance of astrocytes in pathology is yet underappreciated, although astroglia contribute to the pathogenesis of most (if not all) neurological disorders $[2,10]$. In this review we shall focus on the effects of drugs used in neuropsychiatry on astrocytes.

\section{ASTROCYTES IN MAJOR DEPRESSION}

Astroglial reaction to major depression (similarly to other psychiatric pathologies) does not involve astrogliosis and hypertrophy; rather the astrodegenerative signs prevail. The number of astrocytes, and expression of astrogliotic marker GFAP is significantly decreased in the brains of depressed patients (for review, see [14] and references therein). At the same expression of GFAP is increased in the brains of patients treated with antidepressants. Expression of mRNA for another astroglial marker, the calcium binding protein S100? was found to be reduced in the ventral prefrontal cortex of depressed suicide victims. A large scale screening of thirty-six biological markers in thirty inbred mouse strains [15] showed that GFAP and S100제] treatment with fluoxetine (the other two being glyoxylase 1 and histone deacetylase 5). Similarly, reduction in the number of astroglial GFAP-positive profiles and overall GFAP immunoreactivity were detected in several animal models of chronic stress (see [14] and references therein). In animal models selective ablation of astroglial cells (with L-?]-aminoadipic acid, which poisons astrocytes) triggered depressive behavior (see [14] and references therein). Pharmacological inhibition of astroglial gap junction connectivity [16], or astroglial plasmalemmal glutamate transporters [17] resulted in anhedonia, one of the key symptoms of depression. All these findings indicate astrocytic abnormality in the MD.

Contemporary pathophysiology regards imbalance in neurotransmission and, in particular, aberrant glutamatergic neurotransmission as a primary mechanisms for major psychiatric disorders, including major depression [18, 19]. Astrocytes are fundamental elements of glutamatergic and GABAergic neurotransmission being the hubs for glutamate-glutamine and glutamine - GABA shuttles (see above and [20]). In the brains of MD patients, expression of astrocyte-specific glutamate transporters EAAT1/2 as well as of glutamine synthetase is reduced (for review, see [14]), indicating compromised astrocytic uptake glutamate and decreased glutamine production. An increase in glutamate release and a decrease of the glutamate uptake in the hippocampus were also detected following exposure to the chronic unpredictable stress [21]. Decreased glutamate uptake was also observed in the hippocampus, striatum and prefrontal cortex after completion of a learned helplessness paradigm [22]. Experiments in rats showed that blockade of astroglial glutamate uptake was sufficient to decrease sucrose consumption, which is indicative of anhedonia (see [14] and references therein). Furthermore, antidepressant effects of two glutamate modulators, 
ketamine and riluzole have been demonstrated in patients and in animal models ([23] and references therein).

\section{Serotonin-specific reuptake inhibitors' (SSRIs)}

The SSRIs fluoxetine, fluvoxamine, sertraline, paroxetine, and citalopram are, arguably, the most widely used antidepressants around the world. Increased of extracellular concentration of serotonin by inhibition of the serotonin transporter (SERT) has been regarded as SSRI's sole (and undisputed) mechanism of action, despite of the fact that the inhibition of the transporter is instant, whereas the clinical response requires weeks of treatment. Moreover, the relatively high affinity of $5-\mathrm{HT}_{2 B}$ receptor for fluoxetine (see [24] and references therein) was unknown when it was concluded that the SSRIs had no receptor-mediated effects.

Experiments on astrocytes in vitro revealed high levels of expression of $5-\mathrm{HT}_{2 \mathrm{~B}}$ receptors, together with $5-\mathrm{HT}_{2 \mathrm{~A}}$ and $5-\mathrm{HT}_{2}$ receptors as well as non-5- $\mathrm{HT}_{2}$ receptors; the $5-\mathrm{HT}_{2 \mathrm{~B}}$ receptors being indispensable for SSRIs action (see $[8,24]$ and references therein). In addition, cultured astroglial cells express high levels of monoamine oxidase (MAO) A and B, allowing them to metabolise $5-\mathrm{HT}$. Both acute and chronic effects of SSRIs on astrocytes can be suppressed by specific inhibition of $5-\mathrm{HT}_{2 \mathrm{~B}}$ receptors, indicating that SSRIs act as agonists of astroglial $5-\mathrm{HT}_{2 \mathrm{~B}}$ receptors (see [24] and references therein); which conclusion has been independently confirmed [25].

Acute effects of SSRIs

$\underline{5-\mathrm{HT}_{2 B}} \underline{\text { receptors }}$

All astroglial $5-\mathrm{HT}_{2}$ receptors are $\mathrm{G}_{\mathrm{q} / 11}$ protein-coupled; stimulation of these receptors with serotonin activates phospholipase $C$ (PLC), thus generating diacylglycerol (DAG) and inositol 1,4,5-trisphosphate $\left(\operatorname{Ins}_{3}\right)$ by hydrolysis of phosphatidylinositol 4,5-bisphosphate $\left(\mathrm{PIP}_{2}\right)$. The $\mathrm{InsP}_{3}$ in turn activates $\mathrm{InsP}_{3}$ receptors of the endoplasmic reticulum membrane which leads to an increase of free cytosolic calcium concentration $\left(\left[\mathrm{Ca}^{2+}\right]_{i}\right)([5]$ and references therein). The $5-\mathrm{HT}_{2 \mathrm{~B}}$ receptor functionally expressed in astrocytes has much higher affinity to $5-\mathrm{HT}$ than the $5-\mathrm{HT}_{2 \mathrm{~A}}$ and $5-\mathrm{HT}_{2} \mathrm{C}$ receptors [24]. Exposure to fluoxetine triggers an increase in $\left[\mathrm{Ca}^{2+}\right]_{i}$ in cultured astrocytes [24], as well as in astrocytes in brain slices [26]. Cellular calcium signals have numerous targets that may include glycogenolysis, which in astrocytes is stimulated by treatment with fluoxetine ([24]).

\section{ERK signalling cascade}

Acute treatment with fluoxetine at concentrations 1 a $\mathrm{M}$ or higher stimulates $\mathrm{ERK}_{1 / 2}$ phosphorylation [24]. This effect was abolished by broad spectrum 5- $\mathrm{HT}_{2}$ receptors antagonist SB204741, although neither SB242084, a selective 5- $\mathrm{HT}_{2 \mathrm{C}}$ receptor antagonist, nor $\mathrm{M} 100907$, a selective $5-\mathrm{HT}_{2 \mathrm{~A}}$ receptor antagonist, had an effect; hence fluoxetine stimulation of $\mathrm{ERK}_{1 / 2}$ phosphorylation is likely to be mediated through $5-\mathrm{HT}_{2 \mathrm{~B}}$ receptor ([24] and 
references therein). The stimulation of $\mathrm{ERK}_{1 / 2}$ pathway was also abolished by deletion of the $5-\mathrm{HT}_{2 B}$ receptor with small interfering RNAs (siRNAs), further corroborating the above conclusion [24]. The fluoxetine-induced and $5-\mathrm{HT}_{2 \mathrm{~B}}$ receptor-mediated $\mathrm{ERK}_{1 / 2}$ phosphorylation, as well as the effect of fluoxetine on EGFR phosphorylation, could be abolished by both AG1478, an inhibitor of the EGFR tyrosine kinase and by GM6001, a potent and broad-based inhibitor of $\mathrm{Zn}^{2+}$-activated metalloproteinases, suggesting the role for EGF receptor transactivation ([24] and references therein). ERK $1 / 2$ phosphorylated in response to fluoxetine can enter cell nuclei, thus regulating gene expression ([27] and references therein). The mRNA and protein expression of $c f o s$ and $f o s B$ is also induced in astrocytes treated with fluoxetine ([27] and references therein), contingent on $\mathrm{ERK}_{1 / 2}$ phosphorylation.

Chronic effects of SSRIS

$\underline{T h e} \mathrm{Ca}^{2+-}$ dependent phospholipase $\mathrm{A}_{2}$

The $\mathrm{Ca}^{2+-}$ dependent phospholipase $\mathrm{A}_{2}\left(\mathrm{CPLA}_{2}\right.$ IVA) mobilises arachidonic acid, which is a precursor for a multiple physiologically active molecules, including prostaglandins and inflammatory agents [28]. Chronic treatment with fluoxetine led to an up-regulation of $\mathrm{CPLA}_{2}$ in the brain in vivo [24], which is likely to be associated with astrocytes that predominantly express $\mathrm{CPLA}_{2}$ in the grey matter [27]. Chronic treatment with fluoxetine increased expression of $c P L A_{2} m R N A$ and protein in mouse astrocytes in primary cultures in a time and concentration-dependent manner ([27] and references therein). Similarly chronic treatment of cultured astrocytes with other commonly used SSRIs, such as paroxetine, fluvoxamine, sertraline, and citalopram at 1 ?M concentration up-regulates $\mathrm{CPLA}_{2}$ [24]. Chronic treatment of mice with fluoxetine increased expression of $\mathrm{CPLA}_{2}$-specific mRNA solely in astrocytes, as was demonstrated in experiments with fluorescence-activated sorting of neurones and astrocytes in transgenic animals, carrying astroglial (FVB/NTg(GFAP-GFP)14Mes/J) and neuronal (B6.Cg-Tg(Thy1-YFPH)2Jrs/J) markers [27].

Kainate receptors GluK2

Astrocytes express several types of ionotropic and metabotropic glutamate receptors [4]. Kainate GluK2 receptors were identified in astrocytes in hippocampus and in the spinal cord [27]. In astrocytes, glutamate-induced ERK phosphorylation is mediated by GluK2 receptors, as demonstrated by an inhibitory effect of NS102, a specific antagonist of GluK1 and GluK2, and siRNA-induced down-regulation of GluK2 expression ([27] and references therein). Fluoxetine abolishes glutamate-induced $\mathrm{ERK}_{1 / 2}$ phosphorylation and astroglial $\mathrm{Ca}^{2+}$ signals [27], suggesting possible connection with GluK2 editing. Adenosine deaminases acting on RNA's (ADARs) constitute an enzyme family that catalyzes the deamination of adenosine to inosine in double-stranded regions of mRNAs. This changes the translated protein sequence, because inosine is perceived by the cells as guanosine [27]. Fluoxetine up-regulates ADAR2 mRNA and protein expression in cultured astrocytes as well as in astrocytes in the in vivo brain, which may affect GluK2 editing. Indeed, an increased editing of GluK2 was identified by amplification refractory mutation system (ARMS)-PCR (B. Li and L. Peng, unpublished 
results) and by DNA sequencing [29]. It involved three editing sites (I/,$Y / C$ and $Q / R$ sites) of GluK2 in the intact brain in vivo, in cultured astrocytes and in freshly isolated astrocytes [29, 30].

\section{$\underline{5-\mathrm{HT}_{2 \mathrm{~B}}} \underline{\text { receptor }}$}

Up-regulation of expression and RNA editing of the $5-\mathrm{HT}_{2 \mathrm{~B}}$ receptor by chronic treatment with fluoxetine was found in cultured astrocytes (B. Li and L. Peng, unpublished results) and in astrocytes from fluoxetine-treated mice [30]. In cultured astrocytes these changes were inhibited by specific siRNA against the $5-\mathrm{HT}_{2 B}$ receptor. Fluoxetine treatment substantially increased editing at 8 sites in $5-\mathrm{HT}_{2 \mathrm{~B}}$ receptor mRNA between position 793 and position 805, encoding amino acids Ile-Lys-Lys-Pro-lle (5- $\mathrm{HT}_{2 \mathrm{~B}}$ (NM_008311.2)) [30].

\section{Growth factors}

Chronic treatment of primary cultured astrocytes with fluoxetine induced gene expression of brain derived nerve factor (BDNF) and its receptors; likewise this treatment increased expression of glial derived nerve factor (GDNF) and deiodinase 3 (D3) [31, 32]. The SSRIs fluoxetine and paroxetine, but not the tricyclic antidepressants (TCAs), desipramine or imipramine, increased expression of mRNA for BDNF, vascular endothelial growth factor (VEGF) and VGF in cultured astrocytes [33]. Incidentally, increased expression of BDNF by fluoxetine in hippocampal astrocytes may be linked to anxiolytic-like activities [34]. The concomitant induction of neurogenesis, however, is probably not related to the therapeutic effect [35].

\section{Transient receptor potential canonical 1 (TRPC1) channels}

Astroglial $\mathrm{Ca}^{2+}$ signalling, generally regarded as the substrate for glial excitability [10], is mainly generated by $\mathrm{Ca}^{2+}$ release from the ER, mediated by $\operatorname{InsP}_{3}$ receptors ( $\mathrm{Ins}_{3} \mathrm{Rs}$ ) or ryanodine receptors (RyRs), as well as by $\mathrm{Ca}^{2+}$ entry across the cell membrane through $\mathrm{Ca}^{2+}$-permeable channels [10]. The release of $\mathrm{Ca}^{2+}$ from the ER is driven by intra-ER $\mathrm{Ca}^{2+}$ concentration, that in turn reflects a balance between $\mathrm{ER} \mathrm{Ca}^{2+}$ release and $\mathrm{ER} \mathrm{Ca}^{2+}$ refilling. Depletion of ER Ca ${ }^{2+}$ activates "capacitative" $\mathrm{Ca}^{2+}$ entry through store-operated channels (SOCEs). An essential component of SOCEs in astrocytes is the cationic channel TRPC1 [36]. Chronic treatment of astrocytes with fluoxetine reduces neurotransmitter-induced $\mathrm{Ca}^{2+}$ signalling [37], which, in part, reflects TRPC1 dysfunction. In contrast, the same treatment with fluoxetine increased depolarisation-induced $\mathrm{Ca}^{2+}$ entry due to an up-regulation of L-type $\mathrm{Ca}^{2+}$ channels [37]. Incidentally, SSRIs possess an anxiolytic capability, and the quintessential anxiolytic drugs, the benzodiazepines, can also increase depolarisation-induced (i.e. mediated by voltage-gated channels) $\mathrm{Ca}^{2+}$ signals ([24] and references therein).

Astroglial markers, astroglial morphology and density

Chronic treatment with fluoxetine increased the density of S100? 
double labeled with BrdU and receptor for advanced glycation end products (RAGE), the latter being S100]? ? neurogenesis [38] ] An enhanced de novo generation of both astrocytes and neurones is also corroborated by an increase in nucleoside transporter expression in both cells types after fluoxetine treatment of mice $[39,40]$. Increase of serum S100] ] ? observed in patients treated with antidepressants [41]. Nevertheless, neither serum S100? nor BDNF levels reflect their levels in the brain [42], and changes in these proteins in patients with neuropsychiatric diseases should be interpreted with caution. In hippocampal astrocytes in culture and slices, the secretion of S100? ? ? ?induced by fluoxetine? depended on PKA, but not on serotonin [43]. Aquaporin-4 (AQP4) water channels are selectively expressed in astrocytes in the CNS and are concentrated in astrocytic endfeet that plaster blood vessels [44]. Expression of AQP4 is decreased in MD patients [45, 46], and there are some indications that genetic deletion of AQP4 removes antidepressant effect of fluoxetine in chronic mild stress model [47].

The number of astrocytes as wells as their somata volume were decreased in hippocampi of adult tree shrews exposed to chronic stress; treatment with fluoxetine prevented cell loss but not the shrinkage of somata [48]. Repetitive citalopram treatment suppressed kainate-induced reactive astrogliosis and inhibited neurogenesis in hippocampus [49]. Reactive astrocytes are source of and target for inflammatory cytokines. In cultured astrocytes sertraline significantly increased production of an anti-inflammatory cytokine, IL-10, and suppressed production of tumour necrosis factor-? (TNF-? in response to lipopolysaccharide (LPS) [50]. Connexin 43 (Cx 43) channels located in astrocytic processes underlie intercellular communication in astroglial syncytia. Chronic unpredictable stress decreased expression of $\mathrm{C} x 43$ and inhibited diffusion of connexin-permeable dye [16]. This stress-induced decrease of gap junction connectivity was prevented by fluoxetine as well as by serotonin-norepinephrine reuptake inhibitor duloxetine [16].

\section{Serotonin and/or norepinephrine reuptake inhibitors}

Amitriptyline, clomipramine, imipramine, desipramine, nortriptyline belong to tricyclic antidepressants (TCAs). Most of them are supposed to selectively block noradrenaline uptake although desipramine has also some inhibitory effect on serotonin transport. Maprotiline is tetracyclic antidepressant, which suppresses reuptake of both serotonin and norephinephrine, but is less effective against serotonin reuptake. Venlafaxine is a structurally novel inhibitor of serotonin and norepinephrine reuptake.

\section{Growth factors}

Amitriptyline, fluoxetine, clomipramine, mianserin and paroxetine increase synthesis and release of glial cell-derived neurotrophic factor (GDNF) in C6 astrocytoma cell line [51]. Of note, mianserin, being not a reuptake inhibitor, increases norepinephrine release by blocking inhibitory 2 adrenergic receptor. In cultured astrocytes amitriptyline stimulated mRNA expression of fibroblast growth factor-2 (FGF-2), BDNF, VEGF and GDNF [52]. The effect of 
amitriptyline, as well as imipramine on GDNF expression was mediated by MAPK/ERK signal pathway $[53,54]$. In contrast to SSRIs, amitriptyline-induced ERK phosphorylation was mediated by FGF receptor [54]. Imipramine up-regulated BDNF expression in astrocytes [55, 56], this effect being depended on PKA and/or ERK signal pathways [56].

\section{Potassium buffering}

Regulation of ion homeostasis is one of the most fundamental astroglial function [57]. Astroglial $\mathrm{K}^{+}$buffering uptake is mediated, in part, by the $\mathrm{Na}^{+}, \mathrm{K}^{+}$-ATPase [58]. Accumulated $\mathrm{K}^{+}$ is subsequently spatially redistributed through astroglial syncytium and released distantly by an inwardly rectifying $\mathrm{K}_{\mathrm{ir}} 4.1$ channel $[58,59]$. The $\mathrm{K}_{\mathrm{ir}} 4.1$ channel-mediated $\mathrm{K}^{+}$release also decreases the post-stimulatory undershoot [60]. Both tricyclic antidepressants (TCAs) and SSRIs inhibit $\mathrm{K}_{\mathrm{ir}} 4.1$ channels [61-63]. This might alter astrocytic/neuronal interactions in $\mathrm{K}^{+}$ homeostasis and neuronal excitability.

\section{Anti-inflammatory effects}

Cytokines exert both pro- and anti-inflammatory effects [64], and can also have other vital functions [28]. Interleukin (IL)-1 and tumour necrosis factor-?] (TNF-[?]) are pro-inflammatory cytokines. TCAs, clomipramine and imipramine significantly decreased the production of nitric oxide and TNF-? in cultured astrocytes [65]. Imipramine also reduced TNF-? ?]induced inflammatory response [66], and amitriptyline and nortriptyline inhibited the release of IL-1] and TNF-? in mixed glial cultures [67]. In a drug screening with GFAP as the indicator of astrogliosis, chronic treatment of mice with clomipramine for three weeks decreased GFAP expression by nearly $50 \%$ [68]. In contrast to SSRIs, in an in vitro model of ischemia (combined glucose and oxygen deprivation) nortriptyline decreased $\mathrm{CPLA}_{2}$ expression and $\mathrm{CPLA}_{2}$-mediated arachidonic acid release in astrocytes [69], which may reduce production of several proinflammatory compounds.

\section{Other astroglial markers}

Chronic treatment with desipramine decreased the density of 1 and 2 adrenergic receptors in astrocytes in brain in vivo. A decrease of binding of $\left[{ }^{3} \mathrm{H}\right]$-CGP 12177 , a ?-receptor antagonist after 14 days of treatment with reboxetine alone or in combination with sertraline was observed in the olfactory bulb-ectomy rat model of depression and in control animals [70]. In prefrontal cortex of MD patients glucose metabolism was reduced [71]. In cultured astrocytes amitriptyline, clomipramine, mianserine but not imipramine increased ATP content [72]. It was also observed that ATP levels in the brain were lower in mice susceptible to chronic social defeat and administration of ATP reversed depressive-like behaviours, probably through P2X receptors [73], although this latter study is in need of confirmation. The P11 gene has been shown to influence $5-\mathrm{HT}$ transmission and its expression is reduced in animal model of depression and in post-mortem brain tissue of MD patients. The decrease of P11 gene expression is associated with higher DNA methylation of its promoter region and can be reversed by escitalopram, a SSRI [74]. In cultured astrocytes, amitriptyline, 
imipramine and paroxetine decreased the expression of histone methyltransferase G9a, a stimulator of DNA methyltransferase 1, and therefore decreased enzyme activity [75].

\section{Astroglial effects of glutamatergic modulators}

Ketamine

Ketamine is a non-competitive antagonist of NMDA receptor, used primarily for the induction and maintenance of general anaesthesia, usually in combination with a sedative. Ketamine at sub-anaesthetic dose is effective in treating depression in patients with MD and bipolar disorder $[18,23]$. It acts rapidly (within 2 hours) and its antidepressant effects persist for 1-2 weeks [18]. Ketamine induces a rapid and transient increase of glutamate release, which, in turn, stimulates presynaptic group II metabotropic glutamate receptors (mGluRs). The activation of mGluRs induces a long-lasting decrease of glutamate release that possibly compensates the impaired astrocytic glutamate clearance in MD [18].

\section{Riluzole}

Riluzole is the only FDA approved drug for amyotrophic lateral sclerosis (ALS). Riluzole inhibits glutamate release from cultured neurones and brain slices probably by blocking voltage-dependent sodium channels on glutamatergic nerve terminals. Riluzole has antidepressant effect, but no evidence indicates that it acts faster than existing drugs ([23] and references therein). Riluzole increased GLT-1 gene expression and extracellular glutamate clearance in cultured astrocytes and in the in vivo brain $[23,76,77]$. Riluzole also prevented loss of GLT-1 induced by growth factor withdrawal in primary cultures of striatal astrocytes [78]. In addition, riluzole has neuroprotective properties. In cultured mouse astrocytes riluzole up-regulated expression of mRNA and protein of nerve growth factor (NGF), BDNF and GDNF [79]. In C6 cell lines, riluzole activated FGF receptor and its associated intracellular MEK/ERK/CREB signalling pathway, and increased gene expression of GDNF [80].

\section{EXPERT COMMENTARY}

Astroglia have emerged as a potential therapeutic target in psychiatric diseases only very recently, and fundamental knowledge about interactions of anti-psychotic drugs with astroglia are rather limited. Many of the findings discussed above originate from astrocytes in primary cultures, which approach allows for dissection of the basic mechanisms underlying drug action on astrocytes, especially when these compounds are activating or interacting with transporters or receptors. At the same time astrocytes in vitro do not faithfully replicate properties of astroglia in the in vivo brain, and more experiments on animal disease models are needed.

None of the antidepressants have been designed with astrocytes as target in mind. The main mechanism of drug actions in the brain may, however, be mediated by astrocytes (with subsequent neuronal consequences) and could be very different from current concepts, e.g. 
that SSRIs exert their effects mainly via SERT. Moreover, drug effects on astrocytes in cultures and/or astrocytes in brain from healthy animals should also be tested in proper model of the disease in question to establish their relevance. We have found that fluoxetine up-regulates $5-\mathrm{HT}_{2 B}$ receptor, $\mathrm{CPLA}_{2}, \mathrm{ADAR} 2$ and GluK2 in astrocytes, but only the former three are decreased in brain of stress-induced anhedonia animals. However, anhedonia is only one component of major depressive illness and other components should also be investigated.

The investigation of drug effects on astrocytes in normal and pathological conditions will hopefully accelerate new drug development, but this is often a slow process due to adherence to existing dogma by research community and drug companies. This applies not only to the major depression discussed here but also to other neuropsychiatric and neurodegenerative disorders such as for example Alzheimer's disease, where advances in useful drug therapy have been minimal for decades.

\section{FIVE YEAR VIEW}

Astroglia are primary homeostatic and defencive elements of the CNS; and astrocytes contribute to all forms of neuropathologies. The data accumulated in recent decade clearly demonstrated specific changes in astroglia in neuropsychiatric diseases. Precise understanding of pathologically relevant mechanisms associated with astroglia in a context of psychiatric disorders including major depression are the major immediate challenge. Erecting the foundations of astrogliopathology is further frustrated by the absence of proper animal models of human diseases, which is particularly important for neuropsychiatric conditions. So far experimental access to human astroglia is limited to post-mortem tissues. Developments in the in vivo brain imaging, in combination with an emergence of novel astroglia-specific vital markers, as well as wider employment of stem cells derived from humans affected by diseases may offer an avenue for deeper understanding of astroglial pathology. This in turn will provide theoretical background for developing new, astroglial specific therapeutic strategies. Investigations of drug effects on astrocytes in normal and pathological conditions will hopefully accelerate new drug development, but this might be a slow process due to adherence to existing dogma by pharmaceutical companies.

\section{KEY ISSUES}

Astrocytes are highly heterogeneous population of specialised neural cells responsible for homeostasis and defence of the central nervous system.

Astrocytes undergo morphological and functional atrophy in major depression which may contribute to neurotransmission displace and hence to pathological progression.

Antidepressant drugs affect astroglial biochemistry and physiology, which may represent a part of the therapeutic action.

Specific targeting of astroglia may be regarded as a novel strategy in developing 
antidepressant drugs.

\section{Financial and competing interests disclosure}

This study was supported by Grant No. 31171036 to L Peng from the National Natural Science Foundation of China. A Verkhratsky was supported in part by the grant (agreement from August 272013 № 02.B.49.21.0003) between The Ministry of Education and Science of the Russian Federation and Lobachevsky State University of Nizhny Novgorod and by the grant of the Russian Scientific Foundation №14-15-00633. The authors have no other relevant affiliations or financial involvement with any organization or entity with a financial interest in or financial conflict with the subject matter or materials discussed in the manuscript apart from those disclosed. 


\section{REFERENCES}

1. Kettenmann H, Kirchhoff F, Verkhratsky A. Microglia: new roles for the synaptic stripper. Neuron 2013;77:10-8

2. Verkhratsky A, Butt A.M. Glial Physiology and Pathophysiology. Wiley-Blackwell: Chichester, 2013

3. Hertz L. Bioenergetics of cerebral ischemia: a cellular perspective. Neuropharmacol 2008;55:289-309

4. Rose CF, Verkhratsky A, Parpura V. Astrocyte glutamine synthetase: pivotal in health and disease. Biochem Soc Trans 2013;41:1518-24

5. Zhou Y, Danbolt NC. Glutamate as a neurotransmitter in the healthy brain. J Neural Transm 2014;121:799-817

6. Hertz L. Astrocytic energy metabolism and glutamate formation--relevance for 13C-NMR spectroscopy and importance of cytosolic/mitochondrial trafficking. Magn Reson Imaging 2011;29:1319-29

7. Parpura V, Grubišić V, Verkhratsky A. $\mathrm{Ca}^{2+}$ sources for the exocytotic release of glutamate from astrocytes. Biochim Biophys Acta 2011;1813:984-91

8. Hertz L, Rothman DL, Li B,et al. Chronic SSRI stimulation of astrocytic $5-\mathrm{HT}_{2 B}$ receptors change multiple gene expressions/editings and metabolism of glutamate, glucose and glycogen: a potential paradigm shift. Front Behav Neurosci 2015;9:25

9. Verkhratsky A, Parpura V. Verkhratsky, Recent advances in (patho)physiology of astroglia. Acta Pharmacol Sin 2010;31:1044-54

10. Verkhratsky A, Rodriguez JJ Parpura V. Calcium signalling in astroglia. Mol Cell Endocrinol 2012;353:45-56

11. Kirischuk S, Parpura V, Verkhratsky A. Sodium dynamics: another key to astroglial excitability? Trends Neurosci. 2012;35:497-506

12. Muller N, Schwarz MJ. The immune-mediated alteration of serotonin and glutamate: towards an integrated view of depression. Mol Psychiatry 2007;12: 988-1000

13. Hertz L. Astrocytic energy metabolism and glutamate formation--relevance for 13C-NMR spectroscopy and importance of cytosolic/mitochondrial trafficking. Magn Reson Imaging 2011;29:1319-29 
14. Rajkowska G, Stockmeier CA. Astrocyte pathology in major depressive disorder: insights from human postmortem brain tissue.Curr Drug Targets 2013;14:1225-36

15. Benton CS, Miller BH, Skwerer S, et al. Evaluating genetic markers and neurobiochemical analytes for fluoxetine response using a panel of mouse inbred strains. Psychopharmacology (Berl) 2012;221:297-315

16. Sun JD, Liu Y, Yuan YH, Li J, Chen NH. Gap junction dysfunction in the prefrontal cortex induces depressive-like behaviors in rats. Neuropsychopharmacology 2012;37:1305-20

17. Bechtholt-Gompf AJ, Walther HV, Adams MA, et al. Blockade of astrocytic glutamate uptake in rats induces signs of anhedonia and impaired spatial memory. Neuropsychopharmacology 2010;35:2049-59

18. Sanacora G, Treccani G, Popoli M. Towards a glutamate hypothesis of depression: an emerging frontier of neuropsychopharmacology for mood disorders. Neuropharmacology 2012;62:63-77

19. Verkhratsky A, Parpura V. Neurological and psychiatric disorders as a neuroglial failure.Period. Biol 2014;116:115-124

20. Paslakis G, Gass P, Deuschle M. [The role of the glutamatergic system in pathophysiology and pharmacotherapy for depression: preclinical and clinical data]. Fortschr Neurol Psychiatr 2011;79:204-12

21. De Vasconcellos-Bittencourt AP, Vendite DA, Nassif M, et al. Chronic stress and lithium treatments alter hippocampal glutamate uptake and release in the rat and potentiate necrotic cellular death after oxygen and glucose deprivation. Neurochem Res 2011;36:793-800

22. Almeida RF, Thomazi AP, Godinho GF, et al. Effects of depressive-like behavior of rats on brain glutamate uptake. Neurochem Res 2010;35:1164-71

23. Lapidus KA, Soleimani L, Murrough JW. Novel glutamatergic drugs for the treatment of mood disorders. Neuropsychiatr Dis Treat 2013;9:1101-12

24. Hertz L, Li B, Song D, et al. Astrocytes as a $5-\mathrm{HT}_{2 \mathrm{~B}}-$ Mediated SSRI, SERT-independent target, slowly altering depression-associated genes and function. Curr Signal Transduct Ther 2012;7:43-55

25. Diaz SL, Doly $\mathrm{S}$, Narboux-Nême $\mathrm{N}$, et al. $5-\mathrm{HT}_{2 \mathrm{~B}}$ receptors are required for serotonin-selective antidepressant actions. Mol Psychiatry 2012;17:54-63

26. Schipke CG, Heuser I, Peters O. Antidepressants act on glial cells: SSRIs and serotonin 
elicit astrocyte calcium signaling in the mouse prefrontal cortex. J Psychiatr Res 2011;45:242-8

27. Peng $\mathrm{L}$ and Huang J. Astrocytic $5-\mathrm{HT}_{2 \mathrm{~B}}$ receptor as in vitro and in vivo target of SSRIs. Recent Pat CNS Drug Discov 2012;7:243-53

28. Hertz L, Song D, Li B, et al. Importance of 'inflammatory molecules', but not necessarily of inflammation, in the pathophysiology of bipolar disorder and in the mechanisms of action of anti-bipolar drugs. Neurology, Psychiatry and Brain Research 2013;19:174-9

29. Li B, Zhang S, Zhang $\mathrm{H}$, et al. Fluoxetine affects GluK2 editing, glutamate-evoked $\mathrm{Ca}^{2+}$ influx and extracellular signal-regulated kinase phosphorylation in mouse astrocytes. J Psychiatry Neurosci 2011;36:322-38

30. Li B, Dong L, Wang B, et al. Cell type-specific gene expression and editing responses to chronic fluoxetine treatment in the in vivo mouse brain and their relevance for stress-induced anhedonia. J Neurochem Res 2012;37:2480-95

31. Mercier $G$, Lennon AM, Renouf $B$, et al. MAP kinase activation by fluoxetine and its relation to gene expression in cultured rat astrocytes. J Mol Neurosci 2004;24:207-216

32. Prickaerts J, De Vry J, Boere J, et al. Differential BDNF responses of triple versus dual reuptake inhibition in neuronal and astrocytoma cells as well as in rat hippocampus and prefrontal cortex. J Mol Neurosci 2012;48:167-75

33. Allaman I, Fiumelli $\mathrm{H}$, Magistretti PJ, et al. Fluoxetine regulates the expression of neurotrophic/growth factors and glucose metabolism in astrocytes. Psychopharmacology (Berl) 2011;216:75-84

34. Quesseveur G, David DJ, Gaillard MC, et al. BDNF overexpression in mouse hippocampal astrocytes promotes local neurogenesis and elicits anxiolytic-like activities. Transl Psychiatry 2013;3:e253

35. Vollmayr B, Mahlstedt MM, Henn FA. Neurogenesis and depression: what animal models tell us about the link. Eur Arch Psychiatry Clin Neurosci 2007;257:300-3

36. Verkhratsky A, Parpura V. Store-operated calcium entry in neuroglia. Neurosci Bull, 2014;30:125-33

37. Li B, Dong $\mathrm{L}, \mathrm{Fu} \mathrm{H}$, et al. Effects of chronic treatment with fluoxetine on receptor-stimulated increase of $\left[\mathrm{Ca}^{2+}\right]_{i}$ in astrocytes mimic those of acute inhibition of TRPC1 channel activity. Cell Calcium 2011;50:42-53

38. Manev H, Uz T, Manev R. Glia as a putative target for antidepressant treatments. J Affect 
Disord 2003;75:59-64

39. Li B, Gu L, Hertz L, et al. Expression of nucleoside transporter in freshly isolated neurons and astrocytes from mouse brain. Neurochem Res 2013;38:2351-8

40. Nagai K, Konishi H. Effect of fluoxetine and pergolide on expression of nucleoside transporters and nucleic-related enzymes in mouse brain. Fundam Clin Pharmacol 2014;28:217-20

41. Hetzel G, Moeller O, Evers S, et al. The astroglial protein S100B and visually evoked event-related potentials before and after antidepressant treatment. Psychopharmacology (Berl) 2005;178:161-6

42. Luo KR, Hong CJ, Liou YJ, et al. Differential regulation of neurotrophin S100B and BDNF in two rat models of depression. Prog Neuropsychopharmacol Biol Psychiatry 2010;34:1433-9

43. Tramontina AC, Tramontina F, Bobermin LD, et al. Secretion of S100B, an astrocyte-derived neurotrophic protein, is stimulated by fluoxetine via a mechanism independent of serotonin. Prog Neuropsychopharmacol Biol Psychiatry 2008;32:1580-3

44. Nagelhus EA, Veruki ML, Torp R, et al. Aquaporin-4 water channel protein in the rat retina and optic nerve: polarized expression in Müller cells and fibrous astrocytes. J Neurosci 1998;18:2506-19

45. Czéh B, Di Benedetto B. Antidepressants act directly on astrocytes: evidences and functional consequences. Eur Neuropsychopharmacol 2013;23:171-85

46. Bernard R, Kerman IA, Thompson RC, et al. Altered expression of glutamate signaling, growth factor, and glia genes in the locus coeruleus of patients with major depression. Mol Psychiatry 2011;16:634-46

47. Kong H, Sha LL, Fan $Y$, et al. Requirement of AQP4 for antidepressive efficiency of fluoxetine: implication in adult hippocampal neurogenesis. Neuropsychopharmacology 2009;34:1263-76

48. Czéh B, Simon M, Schmelting B, et al. Astroglial plasticity in the hippocampus is affected by chronic psychosocial stress and concomitant fluoxetine treatment. Neuropsychopharmacology 2006;31:1616-26

49. Jaako K, Zharkovsky T, Zharkovsky A. Effects of repeated citalopram treatment on kainic acid-induced neurogenesis in adult mouse hippocampus. Brain Res 2009;1288:18-28

50. Al-Amin MM, Uddin MM, Rahman MM, Reza HM, Rana MS. Effect of diclofenac and antidepressants on the inflammatory response in astrocyte cell culture. 
Inflammopharmacology 2013;21:421-5

51. Hisaoka K, Nishida A, Koda T, et al. Antidepressant drug treatments induce glial cell line-derived neurotrophic factor (GDNF) synthesis and release in rat $\mathrm{C} 6$ glioblastoma cells. J Neurochem 2001;79:25-34

52. Kajitani N, Hisaoka-Nakashima K, Morioka N, et al. Antidepressant acts on astrocytes leading to an increase in the expression of neurotrophic/growth factors: differential regulation of FGF-2 by noradrenaline. PLoS One 2012;7:e51197

53. Kim Y, Kim SH, Kim YS. Imipramine activates glial cell line-derived neurotrophic factor via early growth response gene 1 in astrocytes. Prog Neuropsychopharmacol Biol Psychiatry 2011;35:1026-32

54. Hisaoka K, Tsuchioka M, Yano R, et al. Tricyclic antidepressant amitriptyline activates fibroblast growth factor receptor signaling in glial cells: involvement in glial cell line-derived neurotrophic factor production. J Biol Chem 2011;286:21118-28

55. Kittel-Schneider S, Kenis G, Schek J, et al. Expression of monoamine transporters, nitric oxide synthase 3 , and neurotrophin genes in antidepressant-stimulated astrocytes. Front Psychiatry 2012;3:33

56. Takano K, Yamasaki H, Kawabe K, et al. Imipramine induces brain-derived neurotrophic factor mRNA expression in cultured astrocytes. J Pharmacol Sci 2012;120:176-86

57. Macaulay N, Zeuthen T. Glial $\mathrm{K}^{+}$clearance and cell swelling: key roles for cotransporters and pumps. Neurochem Res 2012;37:2299-309

58. Xu J, Song D, Xue Z, et al. Requirement of glycogenolysis for uptake of increased extracellular $\mathrm{K}+$ in astrocytes: potential implications for $\mathrm{K}^{+}$homeostasis and glycogen usage in brain. Neurochem Res. 2013;38:472-85

59. Hertz L, Xu J, Song D, et al. Brain glycogenolysis, adrenoceptors, pyruvate carboxylase, $\mathrm{Na}^{+}, \mathrm{K}^{+}$-ATPase and Marie E. Gibbs' pioneering learning studies. Front Integr Neurosci 2013;7:20

60. D'Ambrosio R Gordon DS, Winn HR. Differential role of KIR channel and $\mathrm{Na}^{+} / \mathrm{K}^{+}$-pump in the regulation of extracellular $\mathrm{K}^{+}$in rat hippocampus. J Neurophysiol 2002;87:87-102

61. Su S, Ohno Y, Lossin C, et al. Inhibition of astroglial inwardly rectifying $\mathrm{K}_{\mathrm{ir}} 4.1$ channels by a tricyclic antidepressant, nortriptyline. J Pharmacol Exp Ther 2007;320:573-80

62. Ohno $\mathrm{Y}$, Hibino $\mathrm{H}$, Lossin $\mathrm{C}$, et al. Inhibition of astroglial $\mathrm{K}_{\mathrm{ir}} 4.1$ channels by selective serotonin reuptake inhibitors. Brain Res 2007;1178:44-51 
63. Furutani $\mathrm{K}$, Ohno $\mathrm{Y}$, Inanobe A,et al. Mutational and in silico analyses for antidepressant block of astroglial inward-rectifier Kir4.1 channel. Mol Pharmacol 2009;75:1287-95

64. Dinarello CA. Interleukin-18, a proinflammatory cytokine. Eur Cytokine Netw 2000;11:483-6

65. Hwang J, Zheng LT, Ock J, et al. Inhibition of glial inflammatory activation and neurotoxicity by tricyclic antidepressants. Neuropharmacology 2008;55:826-34

66. Lee $\mathrm{YH}, \mathrm{Kim} \mathrm{SH}, \mathrm{Kim} \mathrm{Y}$, et al. Inhibitory effect of the antidepressant imipramine on NF-KB-dependent CXCL1 expression in TNF $\alpha$-exposed astrocytes. Int Immunopharmacol 2012;12:547-55

67. Obuchowicz E, Kowalski J, Labuzek K, et al. Amitriptyline and nortriptyline inhibit interleukin-1 release by rat mixed glial and microglial cell cultures. Int $\mathrm{J}$ Neuropsychopharmacol 2006;9:27-35

68. Cho, $2010 \# 119$ : Cho W, Brenner M, Peters N, et al. Drug screening to identify suppressors of GFAP expression. Hum Mol Genet 2010;19:3169-78

69. Gabryel B, Bielecka A, Stolecka A, et al. Cytosolic phospholipase $A_{2}$ inhibition is involved in the protective effect of nortriptyline in primary astrocyte cultures exposed to combined oxygen-glucose deprivation. Pharmacol Rep 2010;62:814-26

70. Harkin A, Nally R, Kelly JP, et al. Effects of reboxetine and sertraline treatments alone and in combination on the binding properties of cortical NMDA and [1-adrenergic receptors in an animal model of depression. J Neural Transm 2000;107:1213-27

71. Hundal $\varnothing$. Major depressive disorder viewed as a dysfunction in astroglial bioenergetics. Med Hypotheses 2007;68:370-377

72. Trzeciak HI, Pudełko A, Gabryel B, et al. Effect of antidepressants on ATP content, $3 \mathrm{H}$-valine incorporation and cell morphometry of astrocytes cultured from rat brain. Dev Neurosci 1995;17:292-9

73. Cao X, Li LP, Wang Q, et al. Astrocyte-derived ATP modulates depressive-like behaviors. Nat Med 2013;19:773-7

74. Melas PA, Rogdaki M, Lennartsson A, et al. Antidepressant treatment is associated with epigenetic alterations in the promoter of $\mathrm{P} 11$ in a genetic model of depression. Int $\mathrm{J}$ Neuropsychopharmacol 2012;15:669-79 
1

2

3

4

5

6

7

8

9

10

11

12

13

14

15

16

17

18

19

20

21

22

23

24

25

26

27

28

29

30

31

32

33

34

35

36

37

38

39

40

41

42

43

44

45

46

47

48

49

50

51

52

53

54

55

56

57

58

59

60

75. Zimmermann N, Zschocke J, Perisic T, et al. Antidepressants inhibit DNA methyltransferase 1 through reducing G9a levels. Biochem J 2012;448:93-102

76. Gourley SL, Espitia JW, Sanacora G, et al. Antidepressant-like properties of oral riluzole and utility of incentive disengagement models of depression in mice. Psychopharmacology (Berl) 2012;219:805-14

77. Yoshizumi M, Eisenach JC, Hayashida K. Riluzole and gabapentinoids activate glutamate transporters to facilitate glutamate-induced glutamate release from cultured astrocytes. Eur J Pharmacol 2012;677:87-92

78. Carbone M, Duty S, Rattray M. Riluzole elevates GLT-1 activity and levels in striatal astrocytes. Neurochem Int 2012;60:31-8

79. Mizuta I, Ohta M, Ohta K, et al. Riluzole stimulates nerve growth factor, brain-derived neurotrophic factor and glial cell line-derived neurotrophic factor synthesis in cultured mouse astrocytes. Neurosci Lett 2001;310:117-20

80. Tsuchioka M, Hisaoka K, Yano R, et al. Riluzole-induced glial cell line-derived neurotrophic factor production is regulated through fibroblast growth factor receptor signaling in rat $\mathrm{C} 6$ glioma cells. Brain Res 2011;1384:1-8 